\title{
Prostaatkankerrichtlijn: een routekaart in Oncoguide, beslisbomen en informatiestandaard
}

\author{
Antoinette W. de Vries ${ }^{1}$ Floor A. J. Klijn ${ }^{1}$ Robin W. M. Vernooij ${ }^{1}$ Katja H. Aben ${ }^{1}$ Theo M. de Reijke²
}

Published online: 5 February 2019

(c) The Author(s) 2019

\section{Samenvatting}

De Nederlandse richtlijn prostaatkanker is omgezet in beslisbomen, routekaarten dus. Ze staan sinds het najaar van 2018 als digitale beslisondersteuning in Oncoguide. Uit de beslisbomen volgt een informatiestandaard die eenheid van taal creëert en het mogelijk maakt data eenvoudiger te delen en hergebruiken. Door beslisbomen te voorzien van individuele patiënt- en ziektekenmerken leidt Oncoguide de zorgprofessional stap voor stap naar een behandeladvies. Een beslisondersteunende tool zoals Oncoguide geeft een behandeladvies op basis van de landelijke richtlijn, waarvan uiteraard met goede argumentatie afgeweken kan worden. Om de beslisondersteuning tijdens een multidisciplinair overleg (MDO) toepasbaar te maken en patiëntengegevens direct vanuit het MDO in het elektronisch patiëntendossier (EPD) te importeren, is gestructureerde verslaglegging een voorwaarde.

Trefwoorden prostaatkanker $\cdot$ beslisbomen $\cdot$ richtlijn $\cdot$ Oncoguide $\cdot$ multidisciplinair overleg $($ MDO $) \cdot$ registratie

\section{Prostate cancer guideline: a route map in Oncoguide, clinical decision tree and information standard}

\begin{abstract}
The Dutch prostate cancer guidelines have been converted as a route map into decision trees that will be implemented in a digital support system named Oncoguide in the autumn of 2018. Based on the decision trees an information standard can be constructed which creates unity of language and facilitates data sharing and reuse of data. By providing individual patient and disease characteristics to the decision trees, Oncoguide directs the healthcare professional step by step to a treatment advice. A decision support tool such as Oncoguide provides a treatment advice based on the national guidelines. To make the decision support applicable during a MDT and to import patient data directly from the multidisciplinary team meeting (MDT) into the EPD, synoptic reporting is required.
\end{abstract}

Keywords prostate cancer $\cdot$ clinical decision trees $\cdot$ guidelines $\cdot$ Oncoguide $\cdot$ multidisciplinary team meeting (MDT) registration

\section{Introductie}

De Nederlandse Richtlijn prostaatkanker, die werd geaccordeerd door de wetenschappelijke verenigingen, is op 15 september 2016 op Oncoline (www.oncoline.nl) gepubliceerd $[1,2]$. Doordat het proces van het maken van een nieuwe

prof. dr. Theo M. de Reijke

t.m.dereyke@amc.uva.nl

1 Integraal Kankercentrum Nederland, Utrecht, Nederland

2 locatie AMC, Amsterdam UMC, Amsterdam, Nederland richtlijn tot aan de publicatie ervan een paar jaar tijd vergt, ontstond direct na publicatie al behoefte aan een actualisatie van de richtlijn. De volgende update is naar verwachting medio 2019 gereed. Een gemandateerde multidisciplinaire werkgroep ging aan de slag met de revisie van de richtlijn. Om nieuwe behandelmogelijkheden snel op te nemen en aansluiting bij de nieuwste ontwikkelingen uit recent onderzoek te behouden, worden richtlijnen meestal per onderdeel herzien, we noemen dit modulaire revisie. Niet de hele richtlijn wordt geüpdatet, maar alleen die secties waarvoor nieuwe informatie beschikbaar is. Modulaire revisie leidt vaak tot tegenstrijdigheden in richtlijnen, doordat aanpassingen niet consequent worden doorgevoerd [3]. 
Tegelijk met de modulaire richtlijnrevisie is een expertgroep $^{1}$ bestaande uit medische professionals die zijn betrokken bij de behandeling van patiënten met prostaatkanker - samen met Integraal Kankercentrum Nederland (IKNL) - gestart met het omzetten van de Nederlandse Richtlijn Prostaatkanker in beslisbomen. Deze expertgroep was deels ook al betrokken bij de richtlijn. In de tekstuele richtlijn prostaatcarcinoom staat relevante informatie over diagnostiek en behandeling verspreid over verschillende hoofdstukken. De compacte presentatie van een richtlijn in de vorm van beslisbomen kan bij modulaire revisie meer uniformiteit generen. Beslisbomen maken complexe besluitvorming overzichtelijker en dit helpt onduidelijke of tegenstrijdige aanbevelingen te voorkomen.

\section{Beslisbomen}

Een beslisboom zet alle informatie bij elkaar die op een bepaald moment in het diagnose- of behandeltraject voor een patiënt van belang is, laat de verschillende keuzemomenten zien en laat zien hoe het behandeladvies tot stand komt. Het is een andere weergave van de richtlijn: knooppunten in de beslisbomen representeren de patiënt- of ziektekenmerken, de takken de mogelijke uitkomsten daarvan.

Belangrijk is dat de onderbouwing van de aanbevelingen transparant is en behandelaars de mogelijkheid biedt om beslissingen omtrent diagnostiek, behandeling en/of followup van patiënten inzichtelijk te krijgen. Een voordeel van beslisbomen is dat deze interpretabel zijn voor de computer en op termijn behandelbeslissingen automatisch in het EPD kunnen worden vastgelegd.

Tijdens het omzetten van de Nederlandse prostaatkankerrichtlijn in beslisbomen kwam een antal onduidelijkheden en inconsistenties in de richtlijn naar voren. Dit waren onder meer het beleid na biopt (pathologie), beeldvorming bij diagnostiek, risicoclassificatie (Briganti-nomogram), radiotherapie bij lokaal recidief, wel of geen klierdissectie en de volgorde van therapie bij gemetastaseerd castratieresistente prostaatkanker. In overleg met de expertgroep zijn er keuzes gemaakt bij deze momenten en als zodanig ook weergegeven in de beslisboom. De Werkgroep Oncologische Urologie (WOU) van de NVU heeft de op 29 maart 2018 Oncoguide met de beslisboom prostaatcarcinoom geaccordeerd (Fig. 1).

\footnotetext{
1 Aan dit project werkten op persoonlijke titel mee: prof. dr. T.M. de Reijke, uroloog Amsterdam UMC locatie AMC, prof. dr. R.J.A. van Moorselaar, uroloog Amsterdam UMC, locatie VUMC, dr. A.M. Bergman, medisch oncoloog NKI-AVL, prof. dr. W.R. Gerritsen, medisch oncoloog Radboudumc, dr. G.J.L.H. van Leenders, patholoog Erasmus MC, dr. W.V. Vogel, nucleair geneeskundige NKI-AVL, dr. M.C.C.M. Hulshof, radiotherapeut Amsterdam UMC, locatie AMC.
}

\section{Informatiestandaard}

Om patiënt- en ziektekenmerken te kunnen koppelen aan EPD's is 'eenheid van taal' een eerste vereiste [4]. Bij het maken van de beslisbomen is deze eenheid van taal nagestreefd en vastgelegd in een informatiestandaard. Op deze wijze wordt het mogelijk om verschillende computersystemen met elkaar te laten communiceren.

Een informatiestandaard is een verzameling afspraken die gemaakt zijn om zorginformatie eenduidig te kunnen vastleggen, opvragen en uitwisselen [5]. De informatiestandaard faciliteert gestructureerde verslaglegging (synoptic reporting) en deze gestructureerde standaard vastlegging van data faciliteert het meervoudig gebruik van de informatie. Zo realiseert deze methodiek homogeniteit in de verslaglegging van prostaatkankerzorg en vermindert ze de registratielast. Onderzoek heeft bovendien aangetoond dat standaardisering leidt tot betere kwaliteit van die verslaglegging en daarmee tot betere kwaliteit van zorg [6].

In de informatiestandaard staat welke data-items (bijvoorbeeld TNM, PI-RADS) op welke manier (bijvoorbeeld conform TNM-8), op welke plek (bijvoorbeeld in een MDO-verslag of de Nederlandse Kankerregistratie) worden vastgelegd. De informatiestandaard Prostaatkanker is afgestemd op (inter)nationale terminologieën en classificaties en opgesteld in samenwerking met de zorgprofessionals. Voor pathologische data-items heeft afstemming met stichting PALGA plaatsgevonden (www.palga.nl). De beschikbare Zorginformatiebouwstenen zijn hergebruikt [7]. Zorginformatiebouwstenen zijn afspraken over de manier waarop inhoudelijke (niet technische) afspraken die gebruikt worden in het zorgproces vastgelegd moeten worden, als je informatie wilt standaardiseren.

Zonder informatiestandaard is geautomatiseerde informatie-uitwisseling ook mogelijk, maar dan is het maatwerk per uitwisseling (koppeling). In Nederland heeft ieder ziekenhuis vele informatiesystemen in gebruik die informatie met elkaar uitwisselen en hebben ziekenhuizen ook nog hun eigen samenwerkingsverbanden, waarvoor gegevens uitgewisseld worden. Een complex geheel. Door gebrek aan eenheid van taal kan inhoudelijke verwarring ontstaan, bijvoorbeeld over het vastleggen van het stadium van de tumor. De gegevens zijn dan niet eenduidig te interpreteren en automatisch te verwerken door een informatiesysteem.

\section{Oncoguide}

Oncoguide is een routekaart die als digitale beslisondersteuning beschikbaar is als app voor een tablet en via de website [8]. De informatie in Oncoguide is gebaseerd op de oncologische richtlijnen. Deze richtlijnen zijn weergegeven als digitale beslisbomen die leiden tot aanbevelingen voor 
Figuur 1 Beslisboom prostaatcarcinoom

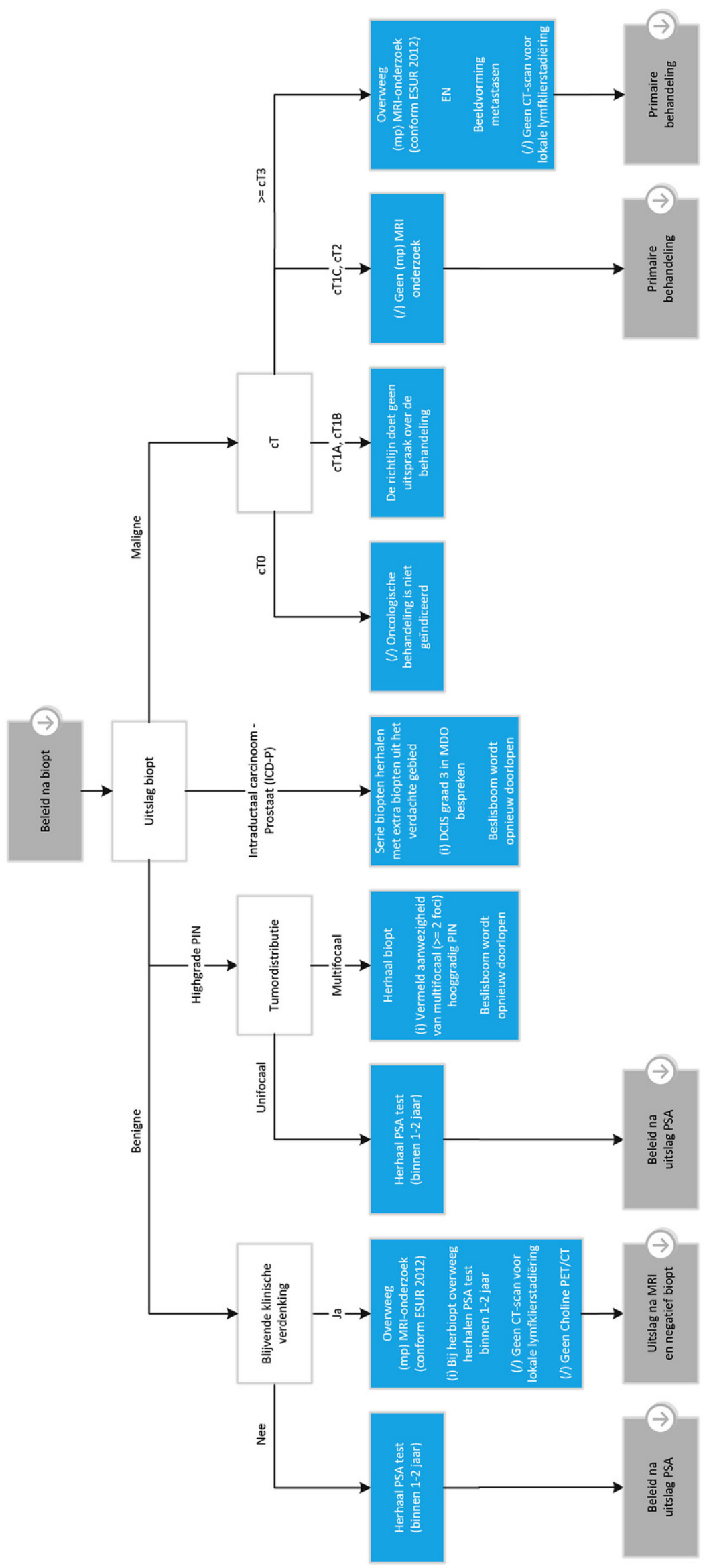


diagnostiek en behandeling. Door individuele patiënt- en ziektekenmerken toe te voegen aan de beslisbomen, komt stap voor stap op transparante wijze een individueel behandeladvies tot stand. De zorgprofessional en patiënt worden als het ware het zorgpad doorgeleid. Bij elke stap worden relevante afwegingen aangegeven en kunnen arts en patiënt besluiten deze te volgen of daarvan gemotiveerd af te wijken.

Oncoguide bevat, net als richtlijnen, aanbevelingen die gebaseerd zijn op de gemiddelde patiënt. Zorgverleners kunnen binnen Oncoguide uiteraard afwijken van het behandeladvies. In Oncoguide is tevens de mogelijkheid opgenomen om feedback te geven: waarom wijkt $u$ in deze situatie af? Welk advies geeft u wel? Die kennis - die nu vrijwel geheel ontbreekt - kunnen expertgroepen en richtlijnwerkgroepen in de toekomst als input gebruiken om de aanbevelingen en richtlijnen te verbeteren.

In de huidige versie van Oncoguide moeten patiënten ziektekenmerken nog handmatig ingevoerd worden. Er wordt gewerkt aan geautomatiseerde koppelingen met EPD's. Dan is handmatig invullen van alle gegevens in Oncoguide niet langer nodig. Het platform om de beslisbomen te raadplegen, kan gekoppeld worden aan een EPD. Oncoguide geeft de arts (en patiënt) inzicht in het optimale behandeladvies voor de individuele patiënt. Oncoguide kan op termijn een rol spelen als hulpmiddel bij gedeelde besluitvorming, waarmee de behandelopties voor de patiënt inzichtelijk worden [9].

Op 22 november 2018 zijn de beslisbomen voor prostaatkanker gepubliceerd in Oncoguide en zijn deze voor iedereen beschikbaar. In samenspraak met expertgroepen, richtlijnwerkgroepen en zorgverleners kunnen de beslisbomen aangepast worden wanneer de nieuwste klinische en wetenschappelijke ontwikkelingen dit nodig achten.

\section{Toekomst}

Tijdens een MDO bespreken de professionals de behandelopties van de patiënten. Oncoguide kan op verschillende manieren in het MDO gebruikt worden: ter voorbereiding door de patiënt- en ziektekenmerken in te voeren en te zien wat de richtlijnaanbeveling is; tijdens het MDO om te discussiëren over de verschillende behandelopties voor de individuele patiënt, of na het MDO in de spreekkamer met de patiënt of tijdens het consult met de verpleegkundige.

Een beslisondersteunende tool zoals Oncoguide geeft een behandeladvies op basis van de landelijke richtlijn. Om de beslisondersteuning tijdens een MDO toepasbaar te maken en patiëntengegevens direct vanuit het MDO in het EPD te importeren, is gestructureerde verslaglegging een voorwaarde. De auteurs willen het gebruik van de Oncoguide prostaatkanker als instrument voor gedeelde besluitvorming in de spreekkamer en tijdens het MDO graag verder onderzoeken. Onze hypothese is dat met behulp van Oncoguide meer inzicht verkregen wordt bij het terecht (of onterecht) afwijken van de richtlijn en dus ook in mogelijk gewenste of ongewenste variatie in verleende zorg.

Een koppeling tussen de trialdatabase van www.kanker. nl en Oncoguide is binnenkort beschikbaar. Dit is een volgende stap in de toepasbaarheid van de beslisbomen. Per ziektestadium worden de relevante trials getoond. Voor de NKR is een efficiëntere registratie mogelijk door meervoudig gebruik van de gestandaardiseerde bronverslaglegging op basis van de informatiestandaard.

\section{Onderzoek}

Samen met Amsterdam UMC gaat IKNL onderzoeken of de behandeladviezen die voortvloeien uit Oncoguide overeenkomen, dan wel afwijken van de behandeladviezen zoals gegeven in reguliere MDO's [10]. Met een variatie van casuïstiek, van veelvoorkomende gevallen tot meer uitzonderlijke prostaatkankerpatiënten, gaan we onderzoeken of het mogelijk is om de patiënten met een MDO-formulier op basis van de informatiestandaard te bespreken.

Ook wordt op korte termijn onderzocht hoe automatische overname van de gegevens uit het pathologieverslag in het MDO-verslag te realiseren is. Een aanzienlijk deel van de gegevens in het MDO-verslag is afkomstig uit het pathologieverslag. Deze pathologische gegevens kunnen synoptisch via het landelijke PALGA-protocol worden verslagen. $\mathrm{Nu}$ worden deze nog handmatig overgetypt. Automatische overname vermindert mogelijke typefouten en registratietijd door zorgverleners. Om gegevens uit het pathologieverslag die relevant zijn voor het MDO, automatisch over te kunnen nemen in het EPD is het noodzakelijk dat het landelijk 'PALGA-protocol prostaat' gebruikt gaat worden [11]. Daarnaast moet een koppeling worden gerealiseerd tussen het pathologie-informatiesysteem in het ziekenhuis en het EPD. Er is op dit moment een aantal pilots gaande in ziekenhuizen om deze innovaties te testen.

Tevens wordt onderzocht hoe het principe van eenmalige registratie en meervoudig gebruik van gegevens gefaciliteerd kan worden. Bijvoorbeeld voor de registratie van gegevens door de zorgverlener in het zorgproces en de aanlevering van de gegevens aan de diverse registraties. Uitgangspunt bij de pilot is dat de gerealiseerde ICT-inrichting schaalbaar en generiek is, zodat deze ook gebruikt kan worden bij MDO's en EPD's van andere ziekenhuizen en voor andere oncologische ziektebeelden. Met behulp van een klinische evaluatie wordt bekeken of de pilot de gewenste resultaten oplevert. 


\section{Conclusie}

Oncoguide biedt op transparantie wijze aan zorgprofessionals en patiënten ondersteuning bij het nemen van behandelbeslissingen en kan een bijdrage leveren aan het verminderen van (ongewenste) variatie van zorg.

Open Access This article is distributed under the terms of the Creative Commons Attribution 4.0 International License (http:// creativecommons.org/licenses/by/4.0/), which permits unrestricted use, distribution, and reproduction in any medium, provided you give appropriate credit to the original author(s) and the source, provide a link to the Creative Commons license, and indicate if changes were made.

\section{Literatuur}

1. Oncoline. Richtlijn prostaatcarcinoom.. https://www.oncoline.nl/ prostaatcarcinoom. Geraadpleegd op: 15 sep 2018.

2. Vernooij R. Updated clinical guidelines: improving their methods and reporting. Barcelona: Universitat Autonoma de Barcelona; 2018. Proefschrift.

3. Raaf DHA de, Groot JJF de, Verbeek XAAM, Huijgens PC. Van klassieke richtlijnen naar digitale beslisondersteuning: behandeladviezen anno 2018. 2018. http://www.ariez.nl/wp-content/uploads/ 2018/08/189-93-1.pdf, NTVO. 2018;15; 189.

4. Rijksinstituut voor Volksgezondheid en Milieu. Eenheid van taal van eenduidige informatie-uitwisseling tot hulpmiddel voor betere zorg. 2017. https://www.informatieberaadzorg.nl/outcomedoelen/ publicaties/publicaties/2017/11/1/wat-is-eenheid-van-taal. Geraadpleegd op: 15 sep 2018.

5. Nictiz - expertisecentrum e-health. Standaardisatie Informatiestandaarden. 2018. https://www.nictiz.nl/standaardisatie/ informatiestandaarden/. Geraadpleegd op: 15 sep 2018.

6. Sluijter CE, Lonkhuijzen LR van, Slooten HJ van, Nagtegaal ID, Overbeek LI. The effects of implementing synoptic pathology reporting in cancer diagnosis: A systematic review. Virchows Arch. 2016;468(6):639-49. Jun.

7. Ministerie van Volksgezondheid, Welzijn en Sport. Zorginformatiebouwstenen. 2017. https://www.nictiz.nl/standaarden/zib/. Geraadpleegd op: 15 sep 2018.

8. Oncoguide. Oncologische zorg. 2018. https://www.iknl.nl/ oncologische-zorg/oncoguide. Geraadpleegd op: 22 nov 2018.

9. Abstract presented on March 23th 2018 at the NCCN Annual Conference in Orlando, Florida, USA (poster 028).

10. IKNL. Bijlage F Eindrapportage voor prostaatkanker. 2014. https://www.kwf.nl/SiteCollectionDocuments/Bijlage\%20F\%20$\% 20$ prostaatkanker.pdf. Geraadpleegd op: 18 sep 2018.

11. Landelijke PALGA Protocol. Prostaatcarcinoom. Utrecht: Stichting PALGA; 2012.

mr. Antoinette W. de Vries senior adviseur

ir. Floor A.J. Klijn klinisch informaticus

dr. Robin W.M. Vernooij post doc onderzoeker

dr. Katja H. Aben senior onderzoeker

prof. dr. Theo M. de Reijke uroloog 